\title{
Physiological stress and reflex impairment of recreationally angled bonefish in Puerto Rico
}

\author{
Jacob W. Brownscombe • Lucas P. Griffin • \\ Tyler Gagne • Christopher R. Haak • Steven J. Cooke • \\ Andy J. Danylchuk
}

Received: 21 February 2015 / Accepted: 24 August 2015 /Published online: 7 September 2015

(C) Springer Science+Business Media Dordrecht 2015

\begin{abstract}
Bonefish (Albula spp.) are a popular target for recreational anglers practicing primarily catch-andrelease $(C \& R)$. The effects of $C \& R$ on bonefish have been previously examined in subtropical regions of The Bahamas. However, it is unclear how these findings relate to larger bonefish, as well as those caught in warmer, tropical environments. Here we examined the effects of C\&R on physiological stress and reflex impairment in bonefish in tropical Culebra, Puerto Rico. Bonefish (Albula vulpes; $56.6 \pm 5.0 \mathrm{~cm}$ total length, mean $\pm \mathrm{SE}$ ) were angled with spinning or fly fishing gear and either handled entirely in the water without air exposure $(n=12)$ or exposed to air for 2 min to simulate an aerial hook removal and admiration period $(n=11)$. Upon capture, bonefish were assessed for the presence of five reflexes and held in floating net pens for $1 \mathrm{~h}$ prior to phlebotomy for quantification of physiological stress. Blood lactate and $\mathrm{pH}$ were correlated with fight time, but linear models showed air exposure and water temperature were better predictors of physiological stress. Compared to previous research using simulated angling events, larger bonefish in warmer water under true angling scenarios had similar physiological stress
\end{abstract}

\footnotetext{
J. W. Brownscombe $(\bowtie) \cdot$ S. J. Cooke

Fish Ecology and Conservation Physiology Laboratory, Ottawa-Carleton Institute for Biology, Carleton University, 1125 Colonel By Dr., Ottawa, ON K1S 5B6, Canada e-mail: jakebrownscombe@gmail.com

L. P. Griffin · T. Gagne · C. R. Haak · A. J. Danylchuk Department of Environmental Conservation, University of Massachusetts Amherst, 160 Holdsworth Way, Amherst, MA 01003, USA
}

responses. Two minutes of air exposure caused significant reflex impairment, which is a strong predictor of post release behavioural impairment and mortality risk in this species. Air exposure should be avoided with bonefish, especially with larger fish and at warmer water temperatures to minimize negative impacts and ensure the sustainability of C\&R bonefish angling.

Keywords Catch-and-release · Fishing · Tropics . Marine $\cdot$ Reflex action mortality predictors

\section{Introduction}

Anglers commonly release fish captured with rod and reel in a practice known as "catch-and-release" (C\&R; Arlinghaus et al. 2007). The reasons that anglers release fish are diverse, but most commonly it is done voluntarily due to conservation ethic or to comply with harvest regulations. While socially and economically valuable (reviewed in Arlinghaus et al. 2007), C\&R can have negative impacts on captured fish due to injuries from the hook or handling, and from physiological stress associated with various aspects of the process (e.g., hooking, fighting, landing, handling, air exposure, retention) that can lead to mortality or reduced fitness post-release (reviewed in Cooke and Suski 2005; Cooke and Schramm 2007). Angler behaviour (e.g., fight duration, handling), environmental conditions (e.g., water temperature, presence of predators), and intrinsic biotic variation (e.g., fish size, inter-specific and interindividual differences in morphology, physiology and 
behaviour) are the primary mediators of these effects (Cooke and Suski 2005). Understanding the nature of these effects and refining best angling practices is key for developing sustainable recreational fisheries and conserving exploited fish populations.

Bonefish (Albula spp.) are a group of 12 species that occupy shallow tropical and sub-tropical seas worldwide (Alexander 1961; Wallace 2014). Bonefish are primarily benthivorous and make frequent feeding migrations between various nearshore habitats, likely serving an important functional role in the allocation of energy throughout coastal areas (Ault 2008; Murchie et al. 2013). They are a highly sought-after sportfish due to their canniness and ability to sustain long powerful fights against anglers who frequently target them with fly or spinning gear (Cooke and Philipp 2008). Given their popularity among anglers and their economic, social and cultural value as sportsfish, many studies have examined the effects of C\&R on bonefish (e.g., Cooke and Philipp 2004; Danylchuk et al. 2007a, b; Suski et al. 2007; Cooke et al. 2008; Brownscombe et al. 2013). Their physiological stress responses have been documented in relation to simulated angling stressors, which were positively correlated with stressor duration and bonefish size (e.g., Suski et al. 2007; Cooke et al. 2008). However, it is well known that angling "simulations" sometimes fail to incorporate key components of the angling process and thus lack realism (Cooke et al. 2013). Simple reflex tests (e.g., whether bonefish are able to maintain upright orientation) have been validated for bonefish and are reflective of angling stressor intensity, and also predictive of post-release behavioural impairment and predation risk (Danylchuk et al. 2007b; Brownscombe et al. 2013). Predation rates can be extremely high, documented up to $40 \%$ during a short period $(\sim 30 \mathrm{~min})$ post-release in areas with high densities of opportunistic predators such as lemon sharks, Negaprion brevirostris and great barracuda, Sphyraena barracuda (Cooke and Philipp 2004; Danylchuk et al. 2007a; Brownscombe et al. 2013).

While a number of studies have examined the effects of angling stressors on bonefish, all of the aforementioned studies were conducted in The Bahamas. Bonefish in this region are fairly unique in their small average body size relative to bonefish in other regions (Pfeiler 2000; C.R. Haak, unpublished data). The Bahamas has a sub-tropical climate and few of the previous studies have been conducted in the summer when water temperatures are highest. Bonefish have a circumtropical distribution and also occupy warmer, tropical waters (Ault 2008). Given that body size and temperature are important factors that influence how fish respond to stressors such as those associated with C\&R (Kieffer 2000; Cooke and Suski 2005), there is a need to better understand the effects of angling on bonefish in other regions with different environmental conditions and population characteristics. Further, many of the previous studies on this species use simulated stressors in the laboratory, which may not be an appropriate representation of actual angling events. Given the importance of handling practices and fish condition on post-release survival in this species, there is also a need to better understand the connections between physiological stress, reflex impairment, and survival of bonefish. Therefore our objective was to examine the effects of recreational angling on bonefish physiological stress and reflex impairment in tropical Puerto Rico using real angling events. We aimed to provide a more thorough understanding of the effects of C\&R angling on bonefish in a different region with potentially more stressful conditions (i.e. warm water), as well as to test whether reflex impairment was reflective of underlying physiological stress, and how angling practices (i.e. air exposure, fight duration) influence these dynamics.

\section{Methods}

Study site

This study was conducted in The Caribbean Sea in the coastal regions of Culebra Island $\left(18.31578^{\circ} \mathrm{N}\right.$, $\left.-65.28763^{\circ} \mathrm{W}\right), 30 \mathrm{~km}$ east of mainland Puerto Rico. Bonefish are a popular target for anglers in Culebra, which are typically tourists fishing with a local fishing guide, or 'do-it-yourself' angling. Bonefish harvest is illegal in Puerto Rico, so legally, bonefish angling is entirely C\&R (DNER 2004). Coastal areas of Culebra contain fringing reefs of hard and soft coral (primaily Diploria, Millepora, Gorgoniidae) transitioning inshore to shallow coral rubble (dead coral fragments) reef crest forming a reef flat. Seagrass beds are common inshore of the reef crest, and primarily composed of turtle grass (Thalassia testudinum), manatee grass (Syrungodium filliforme), and shoal grass (Halodule wrightii), along with macro algae (Halimeda spp., Penicillus spp). The seagrass beds then transition to the deeper-water, soft sediment lagoon zone $(\sim 3-10 \mathrm{~m})$ that separates the reef 
flats from the shoreline. Preliminary genetic analysis suggests bonefish inhabiting these shallow water habitats are entirely Albula vulpes (L. Wallace, unpublished data).

\section{Angling experiments}

Bonefish were angled from the reef crest and seagrass habitats of Culebra's fringing reefs by wading with fly fishing gear (8 weight rods, $6 \mathrm{~kg}$ break strength fluorocarbon leaders with no.5-7 flies) or spinning (mediumheavy strength (7-21 g lure weight) rods, $6 \mathrm{~kg}$ break strength monofilament line with $1 / 0$ octopus hooks and small live crabs $\sim 2 \mathrm{~cm}$ width) gear between 19 June and 01 August 2014. Upon capture, bonefish were either handled entirely in the water to eliminate air exposure $(n=12)$ or exposed to air for $2 \mathrm{~min}$ to simulate an aerial hook removal and admiration period $(n=11)$. Bonefish were then assessed for five reflex action mortality predictors (RAMP; Davis 2010), including tail grab, equilibrium, body flex, head complex, and vestibular-ocular response (VOR). Tail grab involved grabbing the fish's tail while in water; the fish trying to escape the handler indicated a positive response. Equilibrium was assessed by flipping the fish upside down; the fish righting itself within $3 \mathrm{~s}$ indicated a positive response. Body flex was assessed by lifting the fish into air by the center of the body; body flexing as an attempt to escape indicated a positive response. Head complex was tested by observing the fish's operculum; consistent, rhythmic opercular beats indicated a positive response. Lastly, VOR was assessed by rolling the fish side to side in water; a positive response was indicated by the fish's eyes moving up and down to track level. Each test was scored as 1-impaired, 0-unimpaired, which was converted into a proportional value from 0 to 1 . Greater RAMP scores indicate greater impairment (as per Davis 2010). Reflex tests took less than $20 \mathrm{~s}$ to complete. These tests were used because they have been established as effective measures of vitality in a range of teleost fish, including bonefish (Raby et al. 2012; Brownscombe et al. 2013, 2014a; Cooke et al. 2014).

After the RAMP assessment, bonefish were held in a floating mesh net pen $(1.2 \mathrm{~L} \times 1.2 \mathrm{~W} \times 1.2 \mathrm{H} \mathrm{m})$ for $1 \mathrm{~h}$ prior to blood sampling because physiological stress typically peaks $\sim 1 \mathrm{~h}$ post stressor in bonefish (Suski et al. 2007). While this does cause some additional confinement stress, this is the best known approach to retaining fish to observe delayed stress responses or mortality, with a large mesh pen providing sufficient space for movement and constant water flow (Portz et al. 2006; Gutowsky et al. 2015). After the $1 \mathrm{~h}$ holding period, $\sim 1 \mathrm{~mL}$ of blood was drawn via caudal venipuncture using a $21 \mathrm{~g}$ syringe and $3 \mathrm{~mL}$ Vacutainer ${ }^{\circledR}$ (lithium heparin). Blood was analyzed immediately using pointof-care devices calibrated for bonefish (see Cooke et al. 2008; Stoot et al. 2014) for blood-plasma lactate (mmol/L, Lactate Pro LT-1710, Akray Inc., Kyoto, Japan), glucose (mmol/L, Accu-Chek Compact Plus, Roche Diagnostics, Basel, Switzerland) and pH (HI99161, Hanna Instruments, Woonsocket, Rhode Island, USA).

\section{Data analysis}

Bonefish fight times were compared between gear types (fly or spin fishing) with a Welch two-sample t-test. In order to characterize the relationships between various characteristics of the angling events and physiological stress measures, Pearson's r correlations were calculated between fight duration, temperature, fish length, blood glucose, blood lactate, and blood $\mathrm{pH}$. To further elucidate which of these factors were the best predictors of physiological stress, linear models were generated for blood glucose, lactate, and $\mathrm{pH}$, with full candidate models containing air exposure, fight time, temperature, air exposure*fight time, and air exposure*temperature. Fish size was not included as a predictor because it was highly correlated with fight time. The most parsimonious model for each physiological variable was chosen using second-order Akaike Information Criterion (AICc). Physiological variables were also compared amongst categorized RAMP scores: zero $($ RAMP $=0)$, low (0.2-0.4), and high (0.6-0.8) using one-way ANOVAs. RAMP scores were compared between treatments ( 2 min air exposure vs no air exposure) using a Welch two-sample t-test. The level of significance was set at $p \leq 0.05$ and all analyses were conducted using RStudio (v. 0.97.314, R Core Team, Boston, MA).

\section{Results}

A total of 23 bonefish $(56.6 \pm 5.0 \mathrm{~cm}$ total length) were caught by angling with spin fishing gear $(n=11)$ or fly fishing gear $(n=12)$. All bonefish were hooked in the anterior portion of the mouth, primarily at the side of the upper lip, and no deep hooking or bleeding occurred. 
Angling duration (between hooking and landing) ranged from 70 to $245 \mathrm{~s}(145 \pm 50 \mathrm{~s})$, and was positively correlated with fish size (Table 1). Fight times were longer on average on fly fishing gear than spin fishing gear, but there was no significant difference in fight times between gear types $(t=1.5, d f=18.8, p=0.15)$. During holding in the net pen, bonefish remained calm and often stayed still or swam very slowly into the edges of the net. After $1 \mathrm{~h}$ of holding, mean blood glucose concentration was $5.2 \pm 2.1 \mathrm{mmol} / \mathrm{L}$, mean lactate concentration was $13.8 \pm 2.9 \mathrm{mmol} / \mathrm{L}$, and mean $\mathrm{pH}$ was $7.3 \pm 0.2$. Blood lactate concentrations were positively correlated with both temperature and angling duration (Table 1; Fig. 1). Blood pH was negatively correlated with temperature, fight duration, and fish length, while blood glucose was not correlated with any angling metrics (Table 1; Fig. 1). Using linear models, air exposure, fight time, water temperature, and the interaction between fight time and air exposure were not significant predictors of bonefish blood glucose $1 \mathrm{~h}$ post-landing (Table 2). However, temperature was a significant predictor of blood lactate concentrations (Table 2). Surprisingly, lactate concentrations were lower at higher temperatures; however, fight durations were also shorter (and fish sizes smaller) at higher temperatures (Table 1). There was a significant interaction between air exposure and temperature when predicting blood $\mathrm{pH}$ (Table 2), which was negatively correlated with temperature in the no air exposure treatment, but not in the $2 \mathrm{~min}$ air exposure treatment (Fig. 2).

Upon landing, bonefish that were not air exposed had significantly lower reflex impairment scores $(0.1 \pm 0.2$; mean $\pm \mathrm{SD}$; proportion impaired) compared to bonefish that were landed and air exposed for $2 \mathrm{~min}$ $(0.6 \pm 0.1)(t=-9.1, d f=20.3, p<0.001)$. Equilibrium and tail grab were most commonly impaired (100\% of air exposed fish), while body flex and head complex were only impaired in air exposed fish, and VOR was never impaired (Fig. 3). Blood glucose and lactate concentrations were generally higher, and blood $\mathrm{pH}$ lower in fish with high reflex impairment (RAMP score of 0.6 to 0.8 ) than those with low (RAMP score of 0.2 to 0.4 ) or no (RAMP score 0) reflex impairment (Fig. 4); however, there were no significant differences between RAMP score categories in any stress physiology metrics (one-way ANOVA; $\mathrm{F}_{2,20}<2.6, p>0.05$ ).

\section{Discussion}

It is well established that the characteristics of angling events vary greatly due to angler behaviour and gear type (influencing fight times, air exposure periods), as well as environmental factors (e.g., water temperature; Cooke and Suski 2005). This has significant implications for the welfare of fish post-release (Cooke and Sneddon 2007). We examined how various factors influenced physiological stress and reflex impairment in angled bonefish in Culebra, Puerto Rico. Here bonefish tend to be larger, and live in warmer water than their Bahamian counterparts, which have been the focus of all past catch-and-release research (Pfeiler 2000; Suski et al. 2007; Danylchuk et al. 2007a, b; C.R. Haak unpublished data). For example, previous physiological stress research in The Bahamas included bonefish with a mean total length of $45 \mathrm{~cm}$ at $21-23^{\circ} \mathrm{C}$, while this study included bonefish with a mean total length of $57 \mathrm{~cm}$ at 28-32 ${ }^{\circ} \mathrm{C}$. With these larger fish, we observed similar fight durations to previous studies in The Bahamas (Danylchuk et al. 2007a, b). Compared to previous studies (Suski et al. 2007; Cooke et al. 2008), fish here had similar physiological stress responses, aside from a few larger fish with higher lactate concentrations. This could be symptomatic of larger fish size, warmer water temperatures, or greater anaerobic exercise during real angling events than angling simulations in controlled

Table 1 Pearson's $\mathrm{r}$ correlation coefficients (bottom left) and corresponding $p$-values (italicized, top right) for bonefish angling metrics

\begin{tabular}{|c|c|c|c|c|c|c|}
\hline & Total length & Temperature & Fight duration & Glucose & Lactate & $\mathrm{pH}$ \\
\hline Total length & & $0.03 *$ & $0.006^{*}$ & 0.86 & 0.38 & $0.01 *$ \\
\hline Temperature & 0.23 & & 0.56 & 0.27 & $<0.001^{*}$ & $0.03 *$ \\
\hline Fight duration & 0.30 & -0.06 & & 0.09 & $0.01^{*}$ & $0.002 *$ \\
\hline Glucose & 0.02 & -0.12 & 0.19 & & 0.27 & 0.14 \\
\hline Lactate & 0.10 & -0.45 & 0.28 & 0.12 & & 0.49 \\
\hline $\mathrm{pH}$ & -0.26 & -0.24 & -0.34 & -0.16 & 0.08 & \\
\hline
\end{tabular}




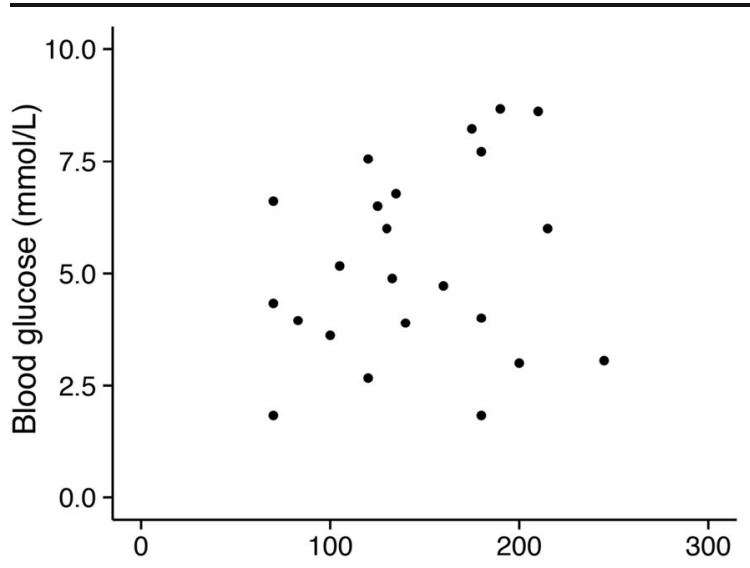

Table 2 Linear model outputs for bonefish blood glucose and lactate concentrations, and blood $\mathrm{pH} 1 \mathrm{~h}$ after angling events

\begin{tabular}{lccc}
\hline Model Variable & Coefficient & $t$-value & $p$-value \\
\hline $\begin{array}{l}\text { Glucose } \\
\quad \text { Intercept }\end{array}$ & 5.2 & 11.8 & $<0.001$ \\
Lactate & & & \\
$\quad$ Intercept & 63.6 & 2.9 & 0.008 \\
$\quad$ Temperature & -1.7 & -2.3 & 0.03 \\
pH & & & \\
$\quad$ Intercept & 11.7 & 7.2 & $<0.001$ \\
$\quad$ Air exposure & -6.2 & -2.6 & 0.02 \\
$\quad$ Temperature & -0.2 & -2.7 & 0.01 \\
$\quad$ Air exposure:Temperature & 0.2 & 2.6 & 0.02 \\
\hline
\end{tabular}

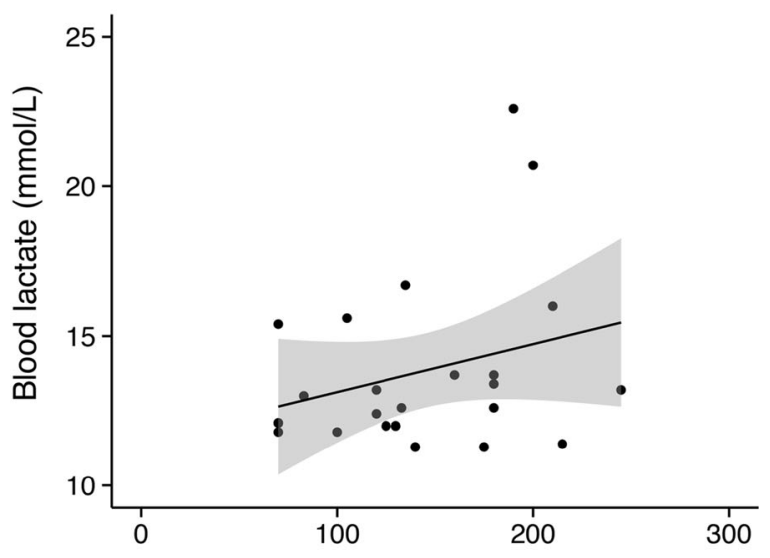

2000; Meka and McCormick 2005). Fight time was also positively correlated with blood lactate concentrations post-capture. However, the best linear models for blood physiology metrics did not include fight time, suggesting it was not a strong predictor compared to other factors such as temperature and air exposure. In conducting C\&R experiments in the wild, it is challenging to untangle the effects of various environmental and angling related factors, which often covary and interact with each other (see Table 1).

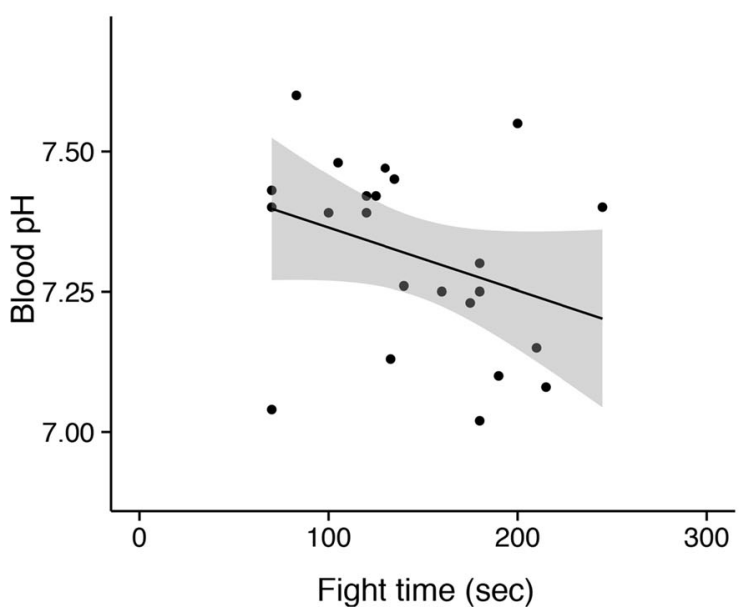

Fig. 1 Relationship between fight duration (s) and bonefish physiological stress responses $1 \mathrm{~h}$ after angling events. Linear models are shown for significant relationships $+/-95 \% \mathrm{CI}$, and statistical results are shown in Table 2

environments. We also observed that larger fish experienced longer fight times and lower blood $\mathrm{pH}$ postcapture suggesting greater metabolic acidosis, which is consistent with C\&R and fish exercise literature (Ferguson et al. 1993; Kieffer et al. 1996; Kieffer

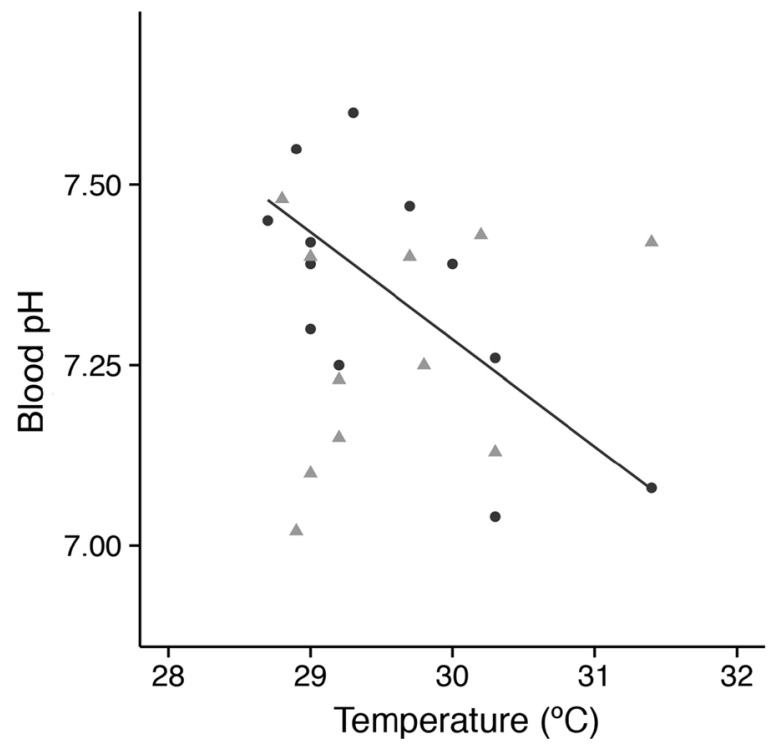

Fig. 2 Relationship between water temperature $\left({ }^{\circ} \mathrm{C}\right)$ and bonefish blood $\mathrm{pH} 1 \mathrm{~h}$ after angling events for fish angled with no air exposure (black circles), or fish angled and air exposed (grey triangles). The line represents the linear relationship for the no air exposure treatment, and statistical results are shown in Table 2 


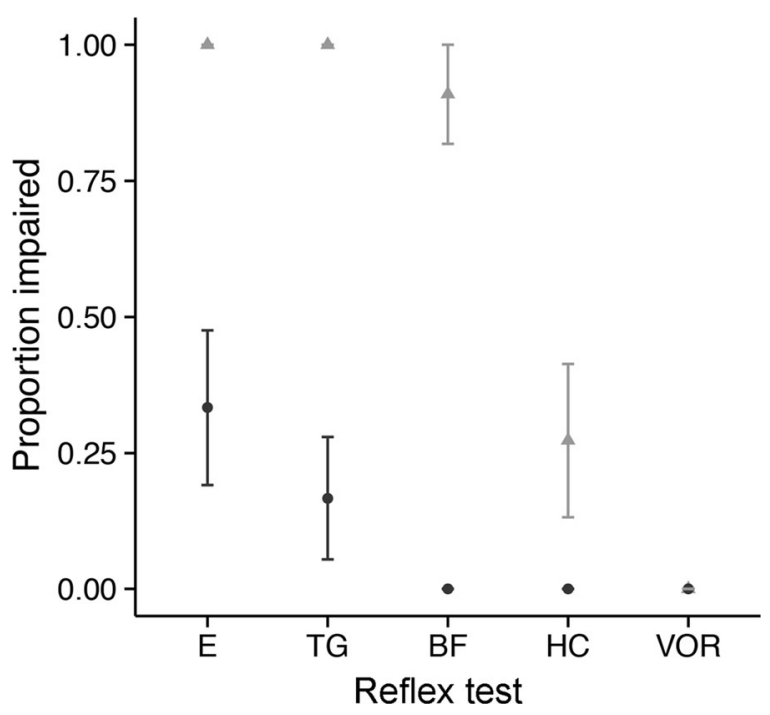

Fig. 3 Proportion of reflexes impaired (reflex action mortality predictors; RAMP) in bonefish immediately after angling events and air exposed for $2 \mathrm{~min}$ (grey triangles) or no air exposure (black circles). $\mathrm{E}=$ equilibrium, $\mathrm{TG}=$ tail grab, $\mathrm{BF}=$ body flex, $\mathrm{HC}=$ head complex, $\mathrm{VOR}=$ vestibular-ocular response

This study was the first to examine physiological stress and reflex impairment in bonefish using actual angling events, opposed to simulations. Importantly, the angling was conducted by experienced bonefish anglers with appropriate fishing gear and tactics to target this species. Using artificial flies, or live crabs on size $1 / 0$ octopus hooks fished actively, we observed no deep hooking and limited hooking-related injury. Given that hooking related injury is considered the primary cause of mortality in angled fish (Muoneke and Childress 1994; Bartholomew and Bohnsack 2005), using appropriate terminal tackle and angling techniques is essential for minimizing the impacts of angling on fish survival and fitness.

Air exposure is considered one of the primary causes of physiological stress in angled fish, and avoiding or minimizing air exposure is consistently recommended by scientists and management agencies (Casselman 2005; Cooke and Suski 2005; Pelletier et al. 2007; Cook et al. 2015). Here we found no significant relationship between 2 min of air exposure and stress physiology metrics, blood glucose and lactate concentrations. There was a significant interaction between air exposure and water temperature for blood $\mathrm{pH}$, but $\mathrm{pH}$ was similar between air exposed and non-air exposed fish (Fig. 2). There was however a significant relationship between air exposure and reflex impairment, which is highly predictive of behavioural impairment and post
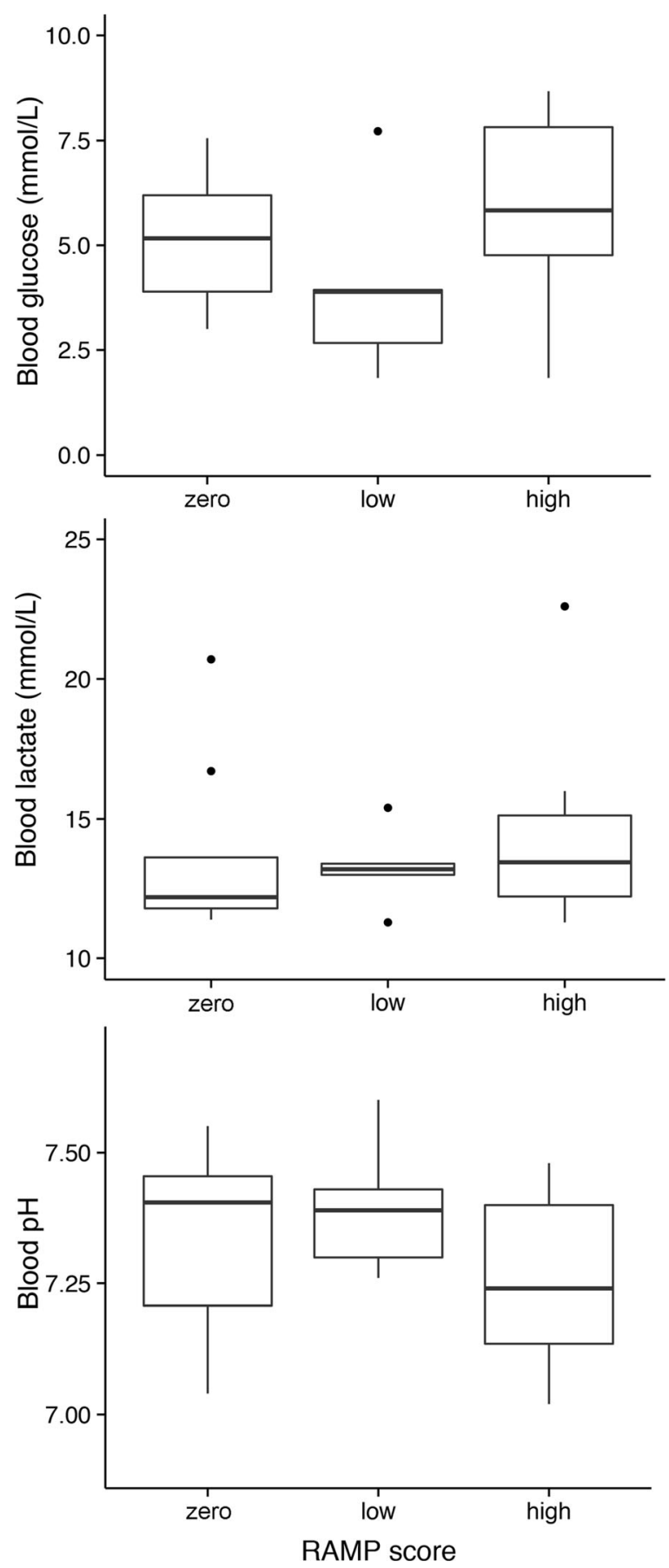

Fig. 4 Bonefish blood glucose and lactate concentrations, and blood $\mathrm{pH} 1 \mathrm{~h}$ after angling events across reflex impairment scores measured upon capture

release mortality (Davis 2010; Raby et al. 2012; Brownscombe et al. 2013), particularly for bonefish due to high post-release predation rates (Danylchuk et al. 2007a; Brownscombe et al. 2013). It is especially 
important for anglers to avoid exposing bonefish to air following capture to reduce behavioural impairment and improve probability of survival. This is easily accomplished in most bonefish fisheries, which occur in shallow water, where anglers often wade.

Reflex tests provide anglers with a valuable tool for assessing the condition of their fish simply and quickly to make educated decisions upon whether to release fish immediately, or employ recovery tactics. Indeed, for bonefish, retaining fish in 'recovery bags' for a short period is beneficial in areas of high predator density due to heightened post-release predation risk in this species (Brownscombe et al. 2013). Consistent with related studies, a lack of equilibrium (also termed orientation) is a particularly useful indicator of fish condition and survival (Danylchuk et al. 2007b; Raby et al. 2012; Brownscombe et al. 2013). Interestingly, while reflex impairment scores did trend positively with physiological stress measures, there were no significant differences in blood physiology across reflex impairment scores. This may be related to our sample sizes, although typical physiological stress metrics often fail to predict reflex and behavioural impairments, as well as mortality in fish (Davis et al. 2001; Davis 2010; Cooke et al. 2013), while reflex tests seem to better capture the whole-body response to a stressor.

Examining physiological stress metrics across angling factors, we observed significant effects of temperature, air exposure, and their interaction on bonefish blood $\mathrm{pH} 1 \mathrm{~h}$ post-capture. While there was no relationship between water temperature and blood $\mathrm{pH}$ in fish exposed to air, there was a strong negative relationship in fish not air exposed (higher temperatures resulted in greater stress). It is possible that the air exposure had a masking effect on this physiological stress measure, and the effect was only apparent in fish that were not air exposed. While the temperature range was relatively small during this study $\left(28\right.$ to $32{ }^{\circ} \mathrm{C}$ ), it is toward the upper thermal limits of bonefish (Murchie et al. 2011; Nowell et al. 2015). Higher temperatures increase metabolic demands in ectothermic fish (Brett 1971), and here bonefish could have greater $\mathrm{CO}_{2}$ accumulation causing greater metabolic acidosis post angling. Blood lactate values were actually lower at higher water temperatures, so lactic acid alone was not the cause of this decrease in blood $\mathrm{pH}$. Presumably, the acidosis was of both respiratory and metabolic origin but we failed to measure blood gasses and thus cannot comment further on these mechanistic aspects.
Here we found that larger bonefish captured in Culebra at warmer water temperatures by real angling events exhibited similar physiological stress responses to their counterparts from The Bahamas exposed to simulated angling stress. Larger fish experienced longer fight durations and greater metabolic acidosis post capture, while blood lactate was positively correlated with fight duration. Two minutes of air exposure caused significant reflex impairment, which is a strong predictor of post release behavioural impairment and mortality risk. Reflex tests are a useful tool for anglers, which can be used as simple and rapid assessments of fish condition, guiding subsequent recovery measures, which may include retention in 'recovery bags', particularly in high predator burden areas. Bonefish are notoriously strong fighters, and fight duration and intensity may be an important predictor of physiological stress and survival relative to other sport fish (Brownscombe et al. 2014b). Air exposure should be avoided with this species, especially with larger fish in warmer water to reduce the negative impacts and ensure the sustainability of C\&R bonefish angling.

Acknowledgments This research has been supported in part by the University of Puerto Rico Sea Grant Program. We like to thank Craig Lilyestrom (Department of Natural and Environmental Resources, Commonwealth of Puerto Rico), Ricardo Colón-Merced and Ana Roman (Culebra National Wildlife Refuges, US Fish and Wildlife Service), Capt. Chris Goldmark, Sammy Hernandez, Zorida Mendez, Todd and Shellie Plaia, and Henry Cruz for their logistical support. We also thank Jim Shulin (Temple Fork Outfitters), Simon Gawesworth (RIO Products), Al Perkinson and Marguerite Meyer (Costa), Brian Bennett (Patagonia/Moldy Chum), and Brian Schmidt (Umpqua) for their in-kind support. Brownscombe is supported by the Natural Sciences and Engineering Research Council of Canada (NSERC). Cooke is supported by NSERC and the Canada Research Chairs program and is a Bonefish and Tarpon Trust Research Fellow. This research was approved by the Canadian Council on Animal Care through the Carleton University Animal Care Committee (application 11473).

\section{References}

Alexander EC (1961) A contribution to the life history, biology and geographical distribution of bonefish, Albula vulpes (Linnaeus). Carlsberg Foundation, Copenhagen

Arlinghaus R, Cooke SJ, Lyman J, Policansky D, Schwab A, Suski CD, Sutton SG, Thorstad EB (2007) Understanding the complexity of catch-and-release in recreational fishing: an integrative synthesis of global knowledge from historical, ethical, social, and biological perspectives. Res Fish Sci 15: $75-167$ 
Ault JS (2008) Biology and management of the world tarpon and bonefish fisheries. CRC Press, Boca Raton

Bartholomew A, Bohnsack JA (2005) A review of catch-andrelease angling mortality with implications for no-take reserves. Rev Fish Biol Fish 15:129-154

Brett JR (1971) Energetic responses of salmon to temperature. A study of some thermal relations in the physiology and freshwater ecology of sockeye salmon (Oncorhynchus nerkd). Am Zool 11:99-113

Brownscombe JW et al. (2013) Recovery bags reduce post-release impairments in locomotory activity and behavior of bonefish (Albula spp.) following exposure to angling-related stressors. J Exp Mar Biol Ecol 440:207-215

Brownscombe JW, Nowell L, Samson E, Danylchuk AJ, Cooke SJ (2014a) Fishing-related stressors inhibit refuge-seeking behavior in released subadult great barracuda. Trans Am Fish Soc 143:613-617

Brownscombe JW, et al. (2014b) The influence of water temperature and accelerometer-determined fight intensity on physiological stress and reflex impairment of angled largemouth bass. Conserv Physiol 2:cou057-cou057

Casselman SJ (2005) Catch-and-release angling: a review with guidelines for proper fish handling practices. Fish and Wildlife Branch, Ontario Ministry of Natural Resources, p 26

Cook KV, Lennox RJ, Hinch SG, Cooke SJ (2015) Fish out of water: How much air is too much?. Fisheries

Cooke SJ, Philipp DP (2004) Behavior and mortality of caughtand-released bonefish (Albula spp.) in Bahamian waters with implications for a sustainable recreational fishery. Biol Conserv 118:599-607e

Cooke SJ, Philipp DP (2008) Improving the sustainability of catch-and-release bonefish (Albula spp.) fisheries: insights for anglers, guides and fisheries managers.. In: Ault J, Kelley G, Humston R (eds) The world biology of tarpon and bonefish. CRC Press, Boca Raton

Cooke SJ, Schramm HL (2007) Catch-and-release science and its application to conservation and management of recreational fisheries. Fish Manag Ecol 14:73-79

Cooke SJ, Sneddon LU (2007) Animal welfare perspectives on recreational angling. Appl Anim Behav Sci 104:176-198

Cooke SJ, Suski CD (2005) Do we need species-specific guidelines for catch-and-release recreational angling to effectively conserve diverse fishery resources? Biodivers Conserv 14: 1195-1209

Cooke SJ, Suski CD, Danylchuk SE, Danylchuk AJ, Donaldson MR, Pullen C, Bulté G, O'Toole A, Murchie KJ, Koppelman JB, Shultz AD, Brooks E, Goldberg TL (2008) Effects of different capture techniques on the physiological condition of bonefish Albula vulpes evaluated using field diagnostic tools. J Fish Biol 73:1351-1375

Cooke SJ, Donaldson MR, O'Connor CM, Raby GD, Arlinghaus R, Danylchuk AJ, Hanson KC, Hinch SG, Clark TD, Patterson DA, Suski CD (2013) The physiological consequences of catch-and-release angling: perspectives on experimental design, interpretation, extrapolation and relevance to stakeholders. Fish Manag Ecol 20:258-287

Cooke SJ, Messmer V, Tobin AJ, Pratchett MS, Clark TD (2014) Refuge-seeking impairments mirror metabolic recovery following fisheries-related stressors in the Spanish flag snapper (Lutjanus carponotatus) on the great barrier reef. Physiol Biochem Zool 87:136-147
Danylchuk AJ, Danylchuk SE, Cooke SJ, Goldberg TL, Koppelman JB, Philipp DP (2007a) Post-release mortality of bonefish (Albula vulpes) exposed to different handling practices during catch-and-release angling in south Eleuthera, Bahamas. Fish Manag Ecol 14:149-154

Danylchuk SE, Danylchuk AJ, Cooke SJ, Goldberg TL, Koppelman J, Philipp DP (2007b) Effects of recreational angling on the post-release behavior and predation of bonefish (Albula vulpes): the role of equilibrium status at the time of release. J Exp Mar Biol Ecol 346:127-133

Davis MW (2010) Fish stress and mortality can be predicted using reflex impairment. Fish Fish 11:1-11

Davis MW, Olla BL, Schreck CB (2001) Stress induced by hooking, net towing, elevated sea water temperature and air in sablefish: lack of concordance between mortality and physiological measures of stress. J Fish Biol 58:1-15

DNER (Commonwealth of Puerto Rico Department of Natural and Environmental Resources) (2004) Puerto Rico fishing regulations. pp. 1-43

Ferguson RA, Kieffer JD, Tufts BL (1993) The effects of body size on the acid-base and metabolite status in the white muscle of rainbow trout before and after exhaustive exercise. J Exp Biol 180:195-207

Gutowsky LFG, Aslam W, Banisaeed R, Bove KL, Burrows GJJ, Chu E, Bell LR, Magel JMT, Rous AM, Brownscombe JW, Cooke SJ (2015) Considerations for the design and interpretation of fishing release mortality estimates. Fish Res 167:64 70

Kieffer JD (2000) Limits to exhaustive exercise in fish. Comp Biochem Physiol A Mol Integr Physiol 126:161-179

Kieffer JD, Ferguson RA, Tompa JE, Tufts BL (1996) Relationship between body size and anaerobic metabolism in brook trout and largemouth bass. Trans Am Fish Soc 125: 760-767

Meka JM, McCormick SD (2005) Physiological response of wild rainbow trout to angling: impact of angling duration, fish size, body condition, and temperature. Fish Res 72:311-322

Muoneke MI, Childress WM (1994) Hooking mortality: a review for recreational fisheries. Rev Fish Sci 2:123-156

Murchie KJ et al. (2011) Thermal biology of bonefish (Albula vulpes) in Bahamian coastal waters and tidal creeks: an integrated laboratory and field study. J Therm Biol 36:38-48

Murchie KJ et al. (2013) Movement patterns of bonefish (Albula vulpes) in tidal creeks and coastal waters of Eleuthera, the Bahamas. Fish Res 147:404-412

Nowell LB, Brownscombe JW, Gutowsky LFG, Murchie KJ, Suski CD, Danylchuk AJ, Shultz A, Cooke SJ (2015) Swimming energetics and thermal ecology of adult bonefish (Albula vulpes): A combined laboratory and field study in Eleuthera, The Bahamas. Environmental Biology of Fishes, BTT Special Issue EBFI-D-14-00224R1

Pelletier C, Hanson KC, Cooke SJ (2007) Do catch-and-release guidelines from state and provincial fisheries agencies in north America conform to scientifically based best practices? Environ Manag 39:760-773

Pfeiler E (2000) Growth rate, age and size of bonefish from the gulf of California. J Fish Biol 56:448-453

Portz DE, Woodley CM, Cech Jr JJ (2006) Stress-associated impacts of short-term holding on fishes. Rev Fish Biol Fish 16:125-170 
Raby GD et al. (2012) Validation of reflex indicators for measuring vitality and predicting the delayed mortality of wild coho salmon bycatch released from fishing gears. J Appl Ecol 49:90-98

Stoot LJ, Cairns NA, Cull F, Taylor JJ, Jeffrey JD, Morin F, Mandelman JW, Clark TD, Cooke SJ (2014) Use of portable blood physiology point- of-care devices for basic and applied research on vertebrates: a review. Conserv Physiol 2: doi:10. 1093/conphys/cou011
Suski CD et al. (2007) Physiological disturbance and recovery dynamics of bonefish (Albula vulpes), a tropical marine fish, in response to variable exercise and exposure to air. Comp Biochem Physiol A Mol Integr Physiol 148: 664-673

Wallace EM (2014) Assessing biodiversity, evolution, and biogeography in bonefishes (Albuliformes): resolving relationships and aiding management. University of Minnesota 